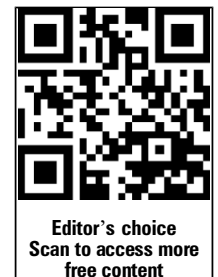

free content

- Additional material is published online only. To view please visit the journal online (http://dx.doi.org/10.1136/ tobaccocontrol-2012-050641).

Department of Health, Behavior and Society, Johns Hopkins Bloomberg School of Public Health, Institute for Global Tobacco Control, Baltimore, Maryland, USA

\section{Correspondence to} Dr Katherine Clegg Smith, Department of Health, Behavior and Society, Johns Hopkins Bloomberg School of Public Health, Institute for Global Tobacco Control, 624 N. Broadway Room 726 Baltimore, MD 21205, USA; kasmith@jhsph.edu

Received 13 June 2012 Revised 4 March 2013 Accepted 7 May 2013 Published Online First 19 June 2013

\title{
Dependence measures for non-cigarette tobacco products within the context of the global epidemic: a systematic review
}

\author{
Elaine De Leon, Katherine Clegg Smith, Joanna E Cohen
}

\begin{abstract}
Objectives Validated metrics of tobacco dependence exist, but their value for global surveillance of tobacco dependence and development of tobacco control interventions is not well understood. This paper reviews tobacco dependence metrics for non-cigarette products, and whether measures of tobacco dependence have been validated in low-income and middle-income countries (LMIC).
\end{abstract}

Data sources Searches were conducted in PubMed, Scopus, PsycINFO, EMBASE, CINAHL and Global Health databases using variant terms for types of tobacco, dependence, measures and validity/reliability. Articles discussing dependence theories and/or metrics were fully reviewed and synthesised.

Study selection Searches yielded 2702 unique articles. Two independent coders identified 587 articles for abstract review, and 229 were subsequently fully reviewed. Findings from 50 eligible papers are summarised.

Data extraction An initial thematic analysis concentrated on four concepts: general tobacco dependence, dependence metrics, tobacco dependence in LMIC and dependence on non-cigarette tobacco.

Data synthesis Analysis identified 14 distinct tobacco dependence instruments. Existing metrics treat tobacco dependence as multifaceted. Measures have been developed almost exclusively around cigarette smoking, although some validation and application across products has occurred. Where cross-national validation has occurred, however, this has rarely included LMIC. Conclusions For purposes of global surveillance of tobacco dependence, there is a compelling need for validated measures to apply universally across social contexts and a multitude of tobacco products. Alternatively, effective tobacco control interventions require validated dependence measures that integrate specific behavioural elements and social context of product use. While different measures of dependence are required to fulfil each of these goals, both have value in addressing the global tobacco epidemic.

\section{BACKGROUND}

Within low-income and middle-income countries (LMIC) that now bear the highest burden of tobacco use, ${ }^{1}$ multiple forms of non-cigarette tobacco are prevalent. $^{2}$ For example, the waterpipe (also known as hookah, shisha, calean and narghile) is popular in countries, such as Egypt, Vietnam, the Russian Federation and Ukraine. In Bangladesh, $27 \%$ of the population uses smokeless tobacco while $11 \%$ smoke bidis (hand rolled cigarette); in India, $26 \%$ of the population uses a smokeless tobacco product while $9 \%$ of the population smoke bidis. Approximately $10 \%$ of the Pakistani population uses non-cigarette tobacco products, including waterpipe, ghutka, paan and naswar (forms of chewing tobacco); $88 \%$ of Indonesian smokers smoke kreteks (clove-flavoured cigarettes). ${ }^{3}$

Because of resources, such as the Global Adult Tobacco Survey (GATS), ${ }^{2}$ the picture of the global prevalence of use of non-cigarette tobacco products is becoming clearer. However, little is known about why these products are used, what properties they hold for users and the barriers faced in quitting. Tobacco dependence, as one such barrier, can be understood as compulsive use of tobacco ${ }^{4-6}$ or as a 'loss of autonomy' over tobacco use. ${ }^{4}$ Use of a product is not synonymous with dependence. Ultimately, dependence is experienced as a need that supersedes others, regardless of whether this need is physiological, psychological or both. Moreover, dependent individuals exist along a continuous scale, from users who are highly dependent to those who use but are minimally dependent. ${ }^{7}$ The individual experience of dependence is mediated by both sociocultural context (eg, cues to use, norms around use, restrictions on use, expectations of use), and behavioural elements (eg, rituals of use, bodily experiences of use).

Until the 'whys' associated with products other than cigarettes are better understood, efforts to address the global tobacco epidemic will be stymied. One important task is to measure dependence on these products; in this regard, there is a need for clear and unifying measures of dependence on all widely used tobacco products. ${ }^{6}$ Colby et $a l^{8}$ argued that the field would greatly benefit from the use of standardised diagnostic measures of nicotine dependence and withdrawal, and Piper et $a l^{9}$ added that improved measures of dependence could provide a greater understanding of the mechanisms for dependence. Understanding dependence on non-cigarette tobacco products may also serve to explain usage patterns. ${ }^{10} 11$

In this review, the state of the literature regarding dependence on various tobacco products in the global context is examined. The key metrics of tobacco dependence are presented, and the extent to which these are applicable to non-cigarette tobacco products and LMIC is considered. We explore how tobacco dependence has been conceptualised and operationalised in the scientific literature, with a particular focus on current capacity to measure dependence on non-cigarette tobacco products, and in LMIC contexts. The goals are threefold: 
- identify seminal measures for dependence

- assess adaptation of measures developed for cigarettes to non-cigarette tobacco products

- find measurements developed in, or validated for, non-cigarette use in the context of LMIC.

\section{METHODS}

In June 2011, electronic searches were conducted in PubMed, Scopus, PsycINFO, EMBASE, CINAHL and Global Health databases. The search was not bound by any dates and, thus, this review was intended to be inclusive, and was subsequently updated in May 2012 to include studies published in the previous year. At each time point, two complementary search strategies were used. The first strategy included variant terms for types of tobacco, in conjunction with terms for dependence, measurements and validity/reliability. The second search strategy used a subset of variant terms for non-cigarette tobacco products using the same dependence and measurement terms, while excluding terms for validity/reliability (see online supplementary table 1). Given the low number of validated studies of dependence for non-cigarette products, the second strategy was intended to generate potential relevant papers on non-cigarette tobacco products. Keywords and controlled vocabulary (medical subject headings) were used in both search strategies and customised to optimally search each database. Search results were exported into a reference manager where duplicates were eliminated.

Articles were included that discussed dependence metrics/ scales, critiques of metrics/scales (checks for reliability/validity), and cross-cultural adaptation of metrics/scales. Articles that discussed only the harm reduction potential of non-cigarette tobacco products were excluded, as were articles reporting dependence prevalence within a given population that did not discuss measurement or metrics. Data and/or metrics focused entirely on withdrawal and/or its symptoms without using such symptoms as direct proxies for dependence, material related to harm reduction, dependence on non-tobacco substances or polysubstance dependence, discussion of dependence and psychiatric illness and scoring clarifications, were all excluded, as they did not deal with core issues of concern for this review.

The inclusion/exclusion process began with a title review by two independent coders (DeLeon and Smith) in order to assess papers' potential relevancy for the review. Titles deemed potentially relevant by both coders were promoted for 'abstract review,' while titles eliminated by both coders were not considered further. Titles where coders disagreed were discussed until consensus was reached. Articles that referred to nicotine dependence-related scales, non-cigarette tobacco, or social factors potentially related to nicotine dependence, were included at this stage.

Abstracts for articles selected for 'abstract review' were read by one coder (DeLeon) and considered for 'full review.' Articles without English translations were excluded at this stage. The results of the abstract review were discussed between DeLeon and Smith. Only articles with a clear focus on defining and/or assessing tobacco dependence with some application to LMIC or non-cigarette products were promoted to 'full review' and included in the final synthesis.

\section{RESULTS}

Figure 1 provides a flowchart of the inclusion and exclusion process for this review. In June 2011, search strategy 1 yielded 2456 results, and search strategy 2 yielded 1568 results; 1495 duplicates were removed from the search results. Out of 2529

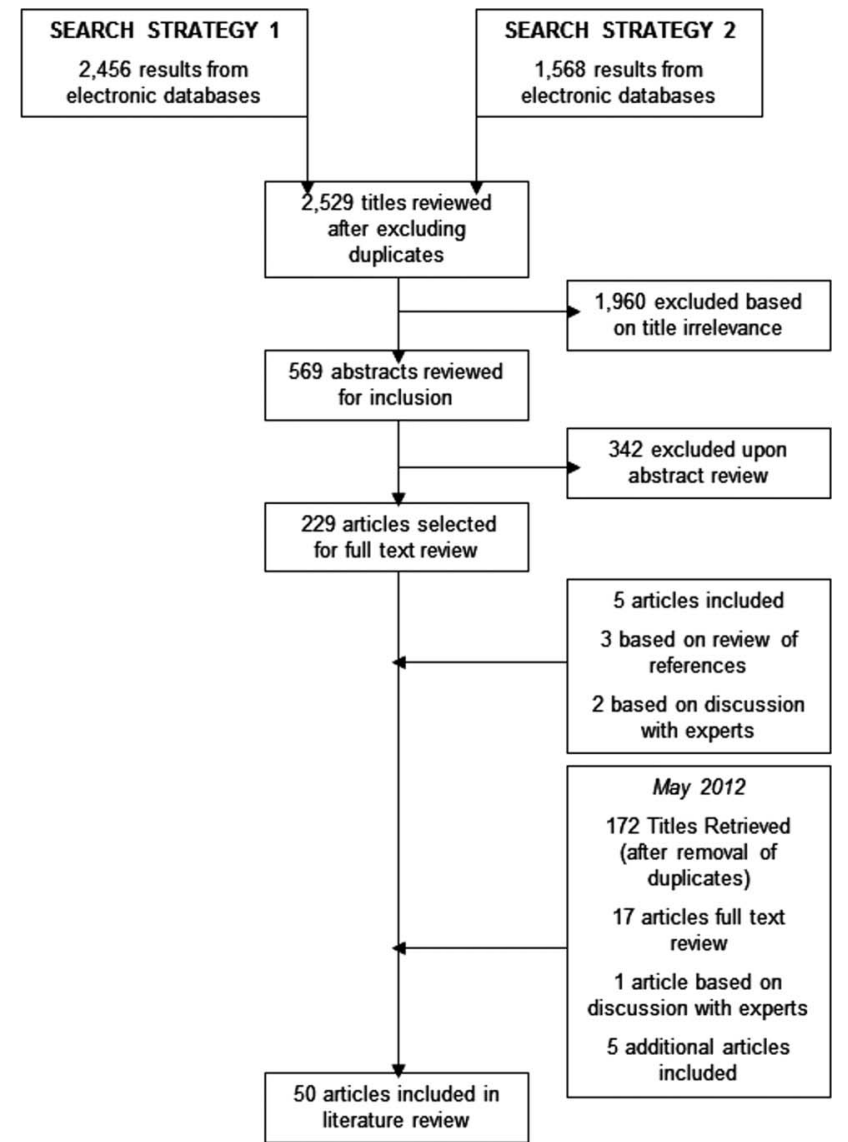

Figure 1 Inclusion/Exclusion process.

titles reviewed, reviewers agreed that 439 abstracts should be reviewed, and disagreed on the inclusion/exclusion of 175 titles (93\% initial reviewer agreement). After consensus discussion regarding each title, 130 out of 175 were subsequently promoted to 'abstract review' in addition to those initially agreed upon for a total of 569 abstracts reviewed. Of these abstracts, 229 were promoted to full article review. Each of these 229 articles was acquired and reviewed, with the exception of articles for which no full text version or English translation was available, after which 45 were identified as making a potential substantive contribution to understanding the measurement of dependence on non-cigarette tobacco in LMIC and were synthesised in this review. This process was repeated in May 2012 to update the review to include work published in the past year; 172 unique titles were identified, 22 were identified for abstract/ full review and four were identified as appropriate for inclusion in the final review. An additional article was added based on the recommendation by an expert in the field of tobacco resulting in a dataset of 50 articles.

\section{Seminal metrics for nicotine dependence}

The review of the 50 articles identified a set of 14 seminal metrics of tobacco dependence (supplementary table 2). For each metric, we summarised the following elements: the definition of dependence, method of development, number of items, features of interest and tobacco products for which it was initially designed and to which it has been subsequently applied.

Even though the Reasons for Smoking Scale (RFS) does not directly assess an individual's level of dependence, we include it as a seminal metric of dependence because of its early influence 
on the field. At one point, this was the most commonly used measure of psychological smoking motives, and it represents one of the first self-reporting measures for smokers. ${ }^{12-14}$

The 14 seminal metrics of dependence identified in table 1 have been used in varying degrees throughout research and clinical practice, with the last metric (DSM V Nicotine Use Disorder) not due for publication until $2013 .{ }^{15}$ In terms of their composition, the metrics range from seven to 68 items. Developmental strategies for the metrics varied widely, from the use of qualitative and formative methods gaining insight from tobacco users, ${ }^{4-18}$ to developmental strategies that prioritised consultation with experts, ${ }^{17}$ 19-22 or the use of items from existing diagnostic tools. ${ }^{18} 2324$ The use of biological measures for measurement development also varied, with some studies using carbon monoxide ${ }^{5172526}$ and salivary/urinary cotinine $e^{5171826}$ to validate the soundness of their metric. The central definitions of dependence for these metrics also vary, but most share an organising principle of tobacco dependence as multifactorial, such that tobacco dependence is assessed according to multiple domains. The important exception to this is the Fagerström Tolerance Questionnaire (FTQ), which was designed explicitly to test only physical dependence on tobacco. ${ }^{21}$ This also applies to the numerous instruments developed out of the FTQ, namely the Fagerström Test for Nicotine Dependence (FTND), ${ }^{27}$ the Heaviness of Smoking Index (HSI), ${ }^{28}$ the modified Fagerström Tolerance Questionnaire (mFTQ) and the Fagerström Tolerance Questionnaire-Smokeless Tobacco (FTQ-ST). ${ }^{29}$ This distinction may contribute to the improved associations with dependence seen with other metrics. 3031

\section{Cross-national adaptation of tobacco dependence measures}

Five of the established measures of tobacco dependence have been adapted for smoking in cross-national contexts. These measures include the FTQ/FTND/mFTQ, Nicotine Dependence Syndrome Scale (NDSS), Hooked on Nicotine Checklist (HONC), the Autonomy Over Smoking Scale (AUTOS), as well as the Modified Reasons for Smoking Scale (MRSS), a measure created using both RFS and WISDM items. ${ }^{32}{ }^{33}$ Generally, few measures have been validated outside of high-income contexts.

The FTQ and/or its variants have been found to be useful for identifying dependent individuals in Spain, ${ }^{34}$ Japan, ${ }^{35}$ France, ${ }^{36}$ Korea, ${ }^{37}$ Turkey, ${ }^{38}$ China, ${ }^{39}{ }^{40}$ Italy $^{41}$ and Argentina. ${ }^{42}$ The cross-national/cross-cultural adaptation of the FTQ/FTND has been found to be only moderately reliable in most instances $(\alpha$ coefficient $=0.55-0.65)$, with the exception of the Korean FTND translation $(\alpha$ coefficient $=0.72),{ }^{37}$ and the Argentinian version of the mFTQ ( $\alpha$ coefficient $=0.88-0.91) .{ }^{42}$ Prior work by Heatherton et $a l^{27}$ also found only moderate reliability crossnationally ( $\alpha$ coefficient for FTQ $=0.41$ and 0.61 for the FTND).

The international utility and applicability of these metrics is not universal; some items were not appropriate in cross-cultural contexts. For example, the FTQ/FTND item referencing smoking more in the morning (ie, 'what cigarette would be most difficult to give up?') was not found to be highly predictive of dependence in France, Turkey or China. ${ }^{36} 3839$ One explanation for this limitation in applicability is that expectations and experiences of tobacco use are heavily culturally bound, such that smoking in the morning may not be a normative behaviour in all settings, moderating the morning cigarette's salience in relation to dependence. The 'difficulty refraining from smoking' item has also been found not to apply as well in the Chinese context where there are still few restrictions on smoking in public spaces. ${ }^{39} 40$ While this item does not hold in China, it was Yamada, Acton and $\mathrm{Tsoh}^{43}$ who identified that Chinese
Americans in the USA who responded to a Chinese version of the FTND were more likely to report 'difficulty in abstaining' in places where smoking is prohibited, presumably because of the stricter regulatory context.

The NDSS was initially developed for alcohol use, but was adapted for tobacco and has subsequently been validated among Finnish $^{44}$ and Spanish smokers. ${ }^{45}$ In Finnish smokers, however, the five-factor model of the NDSS did not fit as adequately as a three-factor model, but was otherwise a sound measure. ${ }^{44}$

Portions of the Wisconsin Inventory of Smoking Dependence Motives (WISDM) have been cross-nationally validated. The first adaptation is through the MRSS, a measure which was first created in Brazil, using a mix of RFS and WISDM criteria for dependence, correlated the MRSS scales of addiction, automatism and affiliative attachment to levels of carbon monoxide exhalation. ${ }^{32}$ The MRSS scale has since also been applied within a Dutch context. ${ }^{46}$ Outside of the WISDM items used in the MRSS, the psychometric properties of the full and brief versions were examined in a Hungarian context by Vajer et al. ${ }^{47}$ Authors were able to validate the brief version of the WISDM with an internet-based sample of treatment-seeking Hungarian smokers. Specifically, four subscales were found to correspond with dependence: automaticity, craving, loss of control and tolerance. The full version suffered from apparent cross-loading (ie, multiple items identifying similar factors) as well as misspecification.

DiFranza et $a l^{42}$ examined the test-retest reliability of the mFTQ, HONC and AUTOS in Argentinean adults and adolescents. The mFTQ, an adaptation of the original FTQ for use in adolescents, ${ }^{48}$ exhibited excellent reliability $(0.88-0.91)$. The HONC (0.85-0.91) and AUTOS (0.91-0.96) scales also exhibited excellent reliability, AUTOS being the most reliable instrument. Wellman et al ${ }^{49}$ subsequently tested the AUTOS in German adolescents; the German translation also demonstrated excellent reliability (0.96).

\section{Measuring dependence on non-cigarette tobacco products}

The review revealed few examples of tobacco dependence measures designed for non-cigarette products. Measures that have been validated for non-cigarette products are even more scarce. Existing diagnostic tools are primarily direct applications or adaptations of metrics developed for cigarette smokers, including the Fagerström Tolerance Questionnaire (FTQ), the Diagnostic Statistical Manual (DSM), the HONC and the AUTOS. In some instances, only certain features from validated metrics for cigarette smoking are applied to addressing dependence on non-cigarette tobacco. Though there is a body of work exploring tobacco dependence in relation to non-cigarette products, the literature is currently largely limited to reporting prevalence rates or health impacts associated with these products. There remains a need to determine best practices for measuring dependence on these products.

\section{Smokeless tobacco}

The FTND, a modified version of the FTQ,${ }^{27}$ has been adapted for smokeless tobacco (snuff and/or chew) users in the form of the FTQ-ST. ${ }^{29}$ The FTQ-ST bases its questions on the Boyle, Jenson, Hatsukami and Severson ${ }^{50}$ modified version of the FTQ for smokeless tobacco and the FTND. ${ }^{27}$ This measure has not, however, been successfully validated. Thomas et $a^{51}$ compared assessment of smokeless tobacco users by the FTQ-ST with the Diagnostic Interview Schedule-IV (questionnaire-based DSM-IV criteria for dependence $)^{52}$ and found poor correlation between the two measures of dependence. Ferketich et $a l^{53}$ tested an 
additional modification of the FTND for smokeless tobacco users, and found only moderate correlation between male smokeless tobacco users' score on the dependence questionnaire and their level of salivary cotinine.

All three smokeless tobacco variations of the FTND included in the review use 'time to first use,' 'using while ill,' 'frequency of use' items, ${ }^{29} 5053$ and two of the three assess 'difficulty refraining. ${ }^{50} 53$ An additional feature unique to smokeless tobacco used in the three studies is the criterion of 'swallowing tobacco juices' during use. Using these variations on the FTND, all studies found moderate correlations between FTND score and the salivary cotinine levels of their respective samples; however, the studies reveal low levels of reliability for these measures. ${ }^{295053}$ Ferketich et $\mathrm{al}^{53}$ called for the development of better metrics of smokeless tobacco dependence.

Following the establishment of poor reliability for the FTND measure adapted for smokeless tobacco, DiFranza, Sweet, Savageau and Ursprung ${ }^{10}$ tested both the HONC ${ }^{4}$ and AUTOS ${ }^{54}$ measures with respect to smokeless tobacco products. The cigarette measures were reworded around use of 'dip' (smokeless tobacco), and applied to US adolescents. Both the HONC and AUTOS proved excellent reliability for smokeless tobacco dependence, ${ }^{10}$ despite the fact that the HONC was created for, and tested with, adolescent cigarette smokers, ${ }^{45-57}$ and the AUTOS for adult smokers. ${ }^{16}$ No difference in dependence was identified between smokeless tobacco or cigarette users by either HONC or AUTOS, or the measure 'latency to withdrawal'.

Given that moist snuff and chew are the smokeless tobacco products used primarily in a Western context, only one study was identified that measured dependence on a tobacco product (paan) used more widely in a LMIC context. ${ }^{58}$ Croucher et $a l^{58}$ found that paan consumers (Bangladeshi women in East London) who had above-average salivary cotinine levels, were four times more likely to have their first paan quid within the first hour of waking ('time to first use') compared with those with below-average cotinine levels. As would be expected, paan consumers who use tobacco leaf were nearly four times more likely to have aboveaverage cotinine levels. Despite the conclusions of this study, there is as yet no self-reporting dependence scale for paan users.

\section{Waterpipe}

Our review confirmed the results from the review conducted by Akl et $a l^{59}$ which identified five validated survey instruments for clinical and epidemiological research of waterpipe use, of which only the Lebanon Waterpipe Dependence Scale (LWDS-11) was directly related to assessing waterpipe dependence ${ }^{26}$ using the FTND and DSM-IV criteria for dependence.

Despite the paucity of measures assessing dependence on waterpipe, established behavioural and contextual features of dependence on this product have been evaluated in epidemiological surveys. Maziak, Ward and Eissenberg ${ }^{60}$ highlighted several factors related to nicotine dependence, including 'smoking mainly alone, at home, smoking more frequently now than when started, hooked on narghile, carrying narghile along if needed, and considering narghile when choosing cafe/restaurant.' Despite similarities with cigarette use, researchers posited that differences in access, preparation and ritual might affect usage patterns. ${ }^{116061}$ Researchers also proposed that dependence would stem from or be indicated by the transition from use of waterpipe as a social activity to that of individual use. ${ }^{60}$

Waked, Salameh and Aoun ${ }^{24}$ assembled a nicotinedependence profile of waterpipe smokers in Lebanon using phone survey responses from waterpipe-only smokers and dual-use waterpipe/cigarette smokers. Though not explicitly stated, many of the survey questions appear to be based upon criteria from nicotine-dependence metrics. The LWDS predictors of tobacco (waterpipe) dependence, 'number of days can stay without waterpipe,' 'number of times stopped WP [waterpipe] for more than seven days' and 'price ready to pay for waterpipe tobacco' (percentage of income on waterpipe smoking) were adapted for this epidemiological survey. Other questions, such as 'time spent searching for waterpipe tobacco,' 'would leave the family on a holiday to buy tobacco,' or 'prefers waterpipe to sport or other activity' allude to the DSM-IV criteria for dependence. Other questions in the survey, 'time to first use of waterpipe' and 'smokes waterpipe even if very sick,' appear to be adaptations of FTQ predictors. ${ }^{24}$

This measure also assesses whether or not waterpipe smokers are 'hooked', through a survey asking whether smokers are interested in quitting and if they believe themselves to be capable of doing so. ${ }^{62}$ Although these criteria were not explicitly used to assess dependence, they are items that can be identified within the DSM-IV, FTQ, Self-Administered Nicotine Dependence Scale (SANDS), Tobacco Dependence Screener (TDS), HONC, WISDM, Cigarette Dependence Scale, and AUTOS metrics for tobacco dependence.

\section{Specialty cigarettes}

Though our search did not identify studies in Bangladesh, India or Indonesia where specialty cigarettes are most likely to be smoked, one US study by Huh and Timberlake ${ }^{63}$ used the subscales of the NDSS and the 'time to first cigarette' feature from the FTND to assess dependence in bidi/kretek-only, conventional cigarette and poly-tobacco users aged 12-25 years. After accounting for the fact that specialty-only smokers smoked significantly less than poly-tobacco users or users of conventional cigarettes, specialty-only smokers were identified as more nicotine dependent using the NDSS/FTND criteria as a result of their shorter time to first cigarette when compared with conventional cigarette smokers.

\section{DISCUSSION}

Our review of the published literature regarding measures of dependence on tobacco products other than cigarettes reveals relatively scant attention to measuring dependence on many of the products widely consumed in LMIC. With regard to the development and validation of measures, the FTQ/FTND/ mFTQ has been translated where necessary, and applied in several countries, including Spain, China, France, Korea, Turkey, Italy and Argentina. The NDSS has been applied with Finnish and Spanish smokers. The MRSS, a metric based on the RFS and WISDM measures for dependence, has been applied in Brazil and The Netherlands. The brief WISDM has been validated for use in Hungary. HONC and AUTOS, like the mFTQ, have been validated in Argentina. However, these represent the few examples of adapted tobacco dependence measures-demonstrating the pressing need for more research on dependence on products commonly used in LMIC.

Tobacco control is now a global endeavour, and dependence measures need to either (1) reflect the various social contexts in which tobacco is used and the characteristics of products consumed, or (2) they should operate in spite of context or product, so that comparisons can be made across countries and products. The limited writing on this issue thus far suggests these two distinct pathways for the development and/or application of dependence measures have not yet been clearly articulated.

In the first instance, dependence is not limited to the physiological/psychological experience of nicotine exposure. Dependence 
is experienced through behaviours (that include acquisition practices, preparations, consumption etc) that are both product specific and set within unique cultural contexts. The social context of tobacco use is clearly relevant to understand patterns of use of various tobacco products, as well as the extent of external pressure to abstain or quit. Up until now, self-reporting instruments used to assess tobacco dependence have been primarily developed for use of cigarette smokers in high-income contexts. Dependence measures that take behavioural and experiential elements into account may be more sensitive within a particular context and time, and for a specific product. To this effect, Baker et $a l^{64}$ have suggested revisions to the proposed DSM-IV criteria for nicotine dependence that account for craving, withdrawal, latency to smoke upon waking and number of cigarettes smoked. Beyond behavioural factors, within a specific time and setting, specific measures could assess where it is permissible to use tobacco products (both in terms of social norms and legally); what is the cost of tobacco use both individually and to one's family; and, how stigmatised tobacco use is among subpopulations (eg, women, religious affiliation, social status). For purposes of development and assessment of tobacco control interventions, it is important to incorporate a consideration of the impact of social and cultural contexts on both the collective conceptualisation and individual experience of dependence. Such measures are not, however, amenable to universal application.

Alternatively, there would be considerable value in a universal measure that would facilitate surveillance and monitoring of tobacco dependence over time and between populations and settings. The FTQ/FTND, the most widely applied dependence measure, is focused entirely on assessing physiological dependence on tobacco, taking a number of behavioural aspects of dependence into account, including the number of cigarettes smoked per day. However, the FTQ/FTND measure has only shown moderate reliability in the majority of contexts where it has been applied. Measures which are relatively free from contextual and cultural influences and focus on physiological experiences of cravings, compulsion and need, such as the HONC and AUTOS, have shown considerable promise in terms of application and evaluation within cross-national contexts and tobacco products other than cigarettes.

The HONC and AUTOS measures have proven to be effective measures of dependence for both cigarette and smokeless tobacco users (specifically adolescent users of snuff/chew), with only minor modifications. These measures are built entirely around physiological symptoms of dependence, and do not incorporate product usage characteristics. Further applications and evaluations of these measures in LMIC is a promising avenue for global dependence measurement.

Turning to non-cigarette tobacco products, the FTQ-ST and the LWDS are the two major examples of measures designed explicitly for use with non-cigarette products. The LWDS also represents the only measure identified created outside of a highincome country (Lebanon).

Both the FTQ-ST and LWDS are based upon criteria found in existing measures of dependence, the FTQ and FTQ/DSM, respectively. However, the modifications incorporate particular aspects of dependence, either behavioural or social, that are specific to using the specific tobacco product.

This literature review benefits from several strengths resulting from its systematic approach. First and foremost, by taking a broad and inclusive systematic approach, a wide array of articles was considered and a more complete understanding of the state of the science regarding non-cigarette tobacco dependence measure could be obtained. Moreover, a consideration of the development and features of seminal measures of dependence serves to better inform the base upon which non-cigarette tobacco dependence measures have, up until this point, been adapted.

One limitation of the review, however, is that because it is intentionally inclusive, quality standards were not set for inclusion of studies. Articles were not evaluated for the rigour of their methodology, but rather for their discussion of noncigarette tobacco dependence or applicability cross-nationally. Additionally, the heterogeneity of articles, including type of tobacco and type of measurement, created difficulties in terms of the assessment of commonalities across measures. This review is also limited by the reach of articles reviewed, which reflects the search terms used within the six databases used, and explicitly excludes dependence measures developed for, or applied to, substance use in general, rather than for tobacco explicitly. It is also possible that the review missed work conducted on dependence reported in the grey literature, or in non-English journals.

Despite these limitations, our findings highlight important areas for additional research. Measures of behavioural and psychological dependence on non-cigarette tobacco products have yet to be fully developed, and the social context has hardly been considered. Few studies address dependence cross-nationally, particularly within LMIC, where the burden of tobacco is increasing rapidly. We see value in both a universal measure, as well as measures that are setting-specific. It is not acceptable, however, for the tobacco control community to simply assume that dependence on non-cigarette products in LMIC can be measured using tools developed and validated in Western settings for a single product. There is much validation and, possibly, developmental work still to be done.

As global tobacco control widens its focus from cigarettes to all tobacco products, there is a need for a collective dialogue about how best to measure dependence. Recent papers by Fagerström and Eissenberg ${ }^{65}$ and DiFranza, Sweet, Savageau et $a l^{10}$ essentially proffer alternate strategies for moving forward. DiFranza, Sweet, Savageau et al ${ }^{10}$ demonstrate cross-product reliability for instruments that are limited to psychometric properties, and argue that this has potential value in measuring dependence in contexts where cigarette use is not the norm. Alternatively, Fagerström and Eissenberg ${ }^{65}$ argue for abandoning the goal of multiproduct instruments due to the critical importance of behavioural components of dependence. On the basis of this review, this debate on dependence measurement might also usefully consider that both these approaches are equally valid and the utility of measures varies depending on whether one's primary goal is surveillance or the development of tobacco control interventions.

\section{What this paper adds}

- Defining and measuring tobacco dependence is a critical and complex task, particularly when one considers the range of tobacco products and the social and policy contexts within which they are consumed. This review examines the application of tobacco dependence metrics to non-cigarette products, as well as the validation and use of dependence metrics in low and middle-income countries (LMIC). We identified 14 distinct tobacco dependence instruments that have been developed almost exclusively around cigarette smoking, and where cross-national validations of instruments have occurred, this has rarely included LMIC. We discuss alternative approaches for tobacco dependence metrics development in the global context. 
Acknowledgements The authors would like to thank Lisa Hepp, Donna Hesson and Andrea Villanti for their assistance with this review.

Contributors All three authors contributed substantively to conceptualising, writing and revising this manuscript. Search terms and strategy were devised collectively. Elaine De Leon and Katherine Smith conducted the initial title and abstract reviews; questionable abstracts and full papers were reviewed with Joanna Cohen. Elaine De Leon led the extraction of variables of interest from included papers.

Funding This work was supported by an award from the Institute for Global Tobacco Control at the Johns Hopkins Bloomberg School of Public Health with funding from the Bloomberg Initiative to Reduce Tobacco Use.

Competing interests None.

Provenance and peer review Not commissioned; externally peer reviewed.

\section{REFERENCES}

1 World Health Organization. Global Health Risks: Mortality and Burden of Disease Attributable to Selected Major Risks, 2009.

2 World Health Organization. Global Adult Tobacco Survey. http://www.who.int/ tobacco/surveillance/gats/en/index.html (accessed 18 May 2012).

3 Campaign For Tobacco Free Kids. Toll of Tobacco Around the World. http://www. tobaccofreekids.org/facts_issues/toll_global/ (accessed 18 Jan 2012).

4 DiFranza JR, Savageau JA, Fletcher K, et al. Measuring the loss of autonomy over nicotine use in adolescents: the DANDY (development and assessment of nicotine dependence in youths) study. Arch Pediatr Adolesc Med 2002;156:397-403.

5 Fagerström KO, Schneider NG. Measuring nicotine dependence: a review of the Fagerström Tolerance Questionnaire. Int J Behav Med 1989:12:159-82.

6 U.S. Department of Health and Human Services. How Tobacco Smoke Causes Disease: The Biology and Behavioral Basis for Smoking-Attributable Disease: A Report of the Surgeon General, 2010.

7 Fagerström K. Commentary on Baker. Assessing dependence-are specific criteria for nicotine enough or do we need to consider its forms of administration? Addiction 2012;107:276-7.

8 Colby SM, Tiffany ST, Shiffman S, et al. Are adolescent smokers dependent on nicotine? A review of the evidence. Drug Alcohol Depend 2000;59(Suppl 1):83-95.

9 Piper ME, McCarthy DE, Baker TB. Assessing tobacco dependence: a guide to measure evaluation and selection. Nicotine Tob Res 2006;8:339-51.

10 Difranza JR, Sweet M, Savageau JA, et al. The assessment of tobacco dependence in young users of smokeless tobacco. Tob Control 2011;21:471-6.

11 Maziak W, Eissenberg T, Ward KD. Patterns of waterpipe use and dependence: implications for intervention development. Pharmacol Biochem Behav 2005;80:173-9.

12 Tate JC, Schmitz JM, Stanton AL. A critical review of the reasons for smoking scale. J Subst Abuse 1991;3:441-55.

13 Tate JC, Stanton AL. Assessment of the validity of the Reasons for Smoking Scale. Addict Behav 1990;15:129-35.

14 Tomkins SS. Psychological model for smoking behavior. Am J Public Health Nations Health 1966;56:17-20

15 Chung T, Martin CS, Maisto SA, et al. Greater prevalence of proposed DSM-5 nicotine use disorder compared to DSM-IV nicotine dependence in treated adolescents and young adults. Addiction 2012;107:810-8.

16 DiFranza JR, Wellman RJ, Ursprung WW, et al. The autonomy over smoking scale. Psychol Addict Behav 2009;23:656-65.

17 Shiffman S, Waters AJ, Hickcox M. The nicotine dependence syndrome scale: a multidimensional measure of nicotine dependence. Nicotine Tob Res 2004;6:327-48.

18 Etter JF, Le Houezec J, Pereger TV. A self-administered questionnaire to measure dependence on cigarettes: the cigarette dependence scale. Neuropsychopharmacology 2003;28:359-70.

19 Yoshii C, Kano M, Isomura T, et al. Innovative questionnaire examining psychological nicotine dependence: the Kano Test for Social Nicotine Dependence (KTSND). J UnivOccup Environ Health 2006:28:45-55.

20 Davis LJ, Hurt RD, Offord KP, et al. Self-Administered Nicotine-Dependence Scale (SANDS): item selection, reliability estimation, and initial validation. J Clin Psycho 1994;50:918-30

21 Fagerström KO. Measuring degree of physical dependence to tobacco smoking with reference to individualization of treatment. Addict Behav 1978;3:235-41.

22 Glover ED, Nilsson F, Westin A, et al. Developmental history of the Glover-Nilsson Smoking Behavioral Questionnaire (GN-SBQ). Am J Health Behav 2005;29:443-55.

23 Kawakami N, Takatsuka N, Inaba S, et al. Development of a screening questionnaire for tobacco/nicotine dependence according to ICD-10, DSM-III-R, And DSM-IV. Addict Behav 1999:24:155-66

24 Waked M, Salameh P, Aoun Z. Water-pipe (narguile) smokers in Lebanon: a pilot study. East Mediterr Health I 2009;15:432-42.

25 Piper ME, Piasecki TM, Federman EB, et al. A multiple motives approach to tobacco dependence: the Wisconsin Inventory of Smoking Dependence Motives (WISDM-68). J Consult Clin Psychol 2004:72:139-54.
26 Salameh P, Waked M, Aoun Z. Waterpipe smoking: construction and validation of the Lebanon Waterpipe Dependence Scale (LWDS-11). Nicotine Tob Res 2008;10:148-59.

27 Heatherton TF, Kozlowski LT, Frecker RT, et al. The Fagerström Test for Nicotine Dependence: a revision of the Fagerström Tolerance Questionnaire. $\mathrm{Br} J$ Addict 1991:86:1119-27.

28 Heatherton TD, Koslowski LT, Frecker RC, et al. Robinson J. Measuring the heaviness of smoking: using self-reported time to the first cigarette of the day and number of cigarettes smoked per day. Br J Addict 1989;84:791-800.

29 Ebbert JO, Patten CA, Schroeder DR. The Fagerström Test for Nicotine Dependence-Smokeless Tobacco (FTND-ST). Addict Behav 2006:31:1716-21.

30 Etter J. Comparing the validity of the Cigarette Dependence Scale and the Fagerström Test For Nicotine Dependence. Drug Alcohol Depend 2008;95:152-9.

31 Wellman RJ, Savageau JA, Godiwala S, et al. A comparison of the Hooked on Nicotine Checklist and the Fagerström Test for Nicotine Dependence in adult smokers. Nicotine Tob Res 2006;8:575-80.

32 de Souza ES, Pasian SR, Martinez JA. University of Sao Paulo reasons for smoking scale: a new tool for the evaluation of smoking motivation. Jornal Brasileiro de Pneumologia: Publicacao Oficial Da Sociedade Brasileira De Pneumoligia E Tisilogia 2010:36:768-78

33 de Souza ES, Crippa JA, Pasian SR, et al. Modified reasons for smoking scale: translation to Portuguese, cross-cultural adaptation for use in Brazil and evaluation of test-retest reliability. Jornal Brazileiro d Pneumologia 2009;35:683-9.

34 Becoña E, Gómez-Durán B, Alvarez-Soto E, et al. Scores of Spanish smokers on Fagerström's Tolerance Questionnaire. Psychol Rep 1992;71:1227-33.

35 Mikami I, Akechi T, Kugaya A, et al. Screening for Nicotine Dependence among smoking-related cancer patients. Cancer Sci 1999;90:1071-5.

36 Chabrol H, Niezborala M, Chastan E, et al. A study of the psychometric properties of the Fagestrom Test for Nicotine Dependence. Addict Behav 2003;28:1441-5.

37 Park SM, Son KY, Lee YJ, et al. A preliminary investigation of early smoking initiation and nicotine dependence in Korean adults. Drug Alcohol Depend 2004;74:197-203

38 Uysal MA, Kadakal F, Karşidağ C, et al. Fagerström test for nicotine dependence: reliability in a Turkish sample and factor analysis. Tuberk Toraks 2004;52:115-21.

39 Huang $\mathrm{C}$, Lin $\mathrm{H}$, Wang $\mathrm{H}$. Psychometric evaluation of the Chinese version of the Fagerström Tolerance Questionnaire as a measure of cigarette dependence. J Adv Nurs 2006:55:596-603.

40 Yang T, Abdullah ASM, Wu J, et al. Nicotine dependence among rural Chinese males. J AddictNursing 2010;21:123-9.

41 Ferketich AK, Fossati R, Apolone G. An evaluation of the Italian version of the Fagerström test for nicotine dependence. Psychol Rep 2008;102:687-94.

42 Difranza JR, Morello P, Gershenson B. The retest reliability of nicotine dependence measures. Addict Res Theory 2012;20:55-63.

43 Yamada H, Acton GS, Tsoh JY. Differential item functioning of the English and Chinese versions of the Fagerström Test for Nicotine Dependence. Addict Behav 2009:34:125-33.

44 Broms U, Madden PA, Heath AC, et al. The Nicotine dependence syndrome scale in finnish smokers. Drug Alcohol Depend 2007;89:42-51.

45 Becoña E, López A, Fernández del Río E, et al. Spanish adaptation of the NDSS (Nicotine Dependence Syndrome Scale) and assessment of nicotine-dependent individuals at primary care health centers in Spain. Span J Psychol 2010;13:951-60

46 Boudrez H, De Bacquer D. A Dutch version of the modified reasons for smoking scale: factorial structure, reliability and validity. I Eval Clin Pract 2011.

47 Vajer P, Urbán R, Tombor I, et al. Psychometric properties and construct validity of the Brief Wisconsin Inventory of Smoking Dependence Motives in an internet-based sample of treatment-seeking Hungarian smokers. Nicotine Tob Res 2011;13:273-81.

48 Prokhorov AV, De Moor C, Pallonen UE, et al. Validation of the Modified Fagerström Tolerance Questionnaire with salivary cotinine among adolescents. Addict Behav 2000;25:429-33.

49 Wellman RJ, Di Franza JR, Morgenstern M, et al. Psychometric properties of the Autonomy over Tobacco Scale in German. Eur Addict Res 2012;18:76-82.

50 Boyle RG, Jensen J, Hatsukami DK, et al. Measuring dependence in smokeless tobacco users. Addict Behav 1995;20:443-50.

51 Thomas JL, Ebbert JO, Patten CA, et al. Measuring nicotine dependence among smokeless tobacco users. Addict Behav 2006;31:1511-21.

52 American Psychiatric Association. Diagnostic and Statistical Manual of Mental Disorders. 4th ed. Washington, D.C: American Psychiatric Association, 2000.

53 Ferketich AK, Wee AG, Shultz J, et al. Smokeless tobacco use and salivary cotinine concentration. Addict Behav 2007:32:2953-62.

54 DiFranza J, Ursprung WWS, Lauzon B, et al. A systematic review of the Diagnostic and Statistical Manual diagnostic criteria for nicotine dependence. Addict Behav 2010;35:373-82.

55 O'Loughlin J, DiFranza J, Tyndale RF, et al. Nicotine-dependence symptoms are associated with smoking frequency in adolescents. Am J Prev Med 2003;25:219-25.

56 O'Loughlin J, DiFranza J, Tarasuk J, et al. Assessment of nicotine dependence symptoms in adolescents: a comparison of five indicators. Tob Control 2002:11:354-60. 
57 Wellman RJ, McMillen R, DiFranza JR. Assessing college students' autonomy over smoking with the Hooked On Nicotine Checklist. J Am Coll Health 2008;56:549-63.

58 Croucher $\mathrm{R}$, Islam $\mathrm{S}$, Jarvis $\mathrm{M}$, et al. Tobacco dependence in a UK Bangladesh female population: a cross-sectional study. Nicotine Tob Res 2002;4:171-6.

59 Akl EA, Aleem S, Gunukula SK, et al. Survey instruments used in clinical and epidemiological research on waterpipe tobacco smoking: a systematic review. BMS Public Health 2010;10:415.

60 Maziak W, Ward KD, Eissenberg T. Factors related to frequency of narghile (waterpipe) use: the first insights on tobacco dependence in narghile users. Drug Alcohol Depend 2004;76:101-6.
61 Maziak W. The waterpipe: time for action. Addiction 2008;103:1763-7.

62 Ward KD, Hammal F, VanderWeg MW, et al. Are waterpipe users interested in quitting? Nicotine Tob Res 2005;7:149-56.

63 Huh J, Timberlake DS. Do smokers of specialty and conventional cigarettes differ in their dependence on nicotine? Addict Behav 2009:34:204-11.

64 Baker TB, Breslau N, Covey L, et al. DSM criteria for tobacco use disorder and tobacco withdrawal: a critique and proposed revisions for DSM-5. Addiction 2012;107:263-75.

65 Fagerström K, Eissenberg T. Dependence on tobacco and nicotine products: a case for product-specific assessment. Nicotine Tob Res 2012;14:1382-90. 